\title{
Prevalence and Knowledge on Obesity Among School Going Adolescents of Kaski, Nepal
}

\author{
Pandey $A^{1}$, Sapkota $S^{2}$
}

\begin{abstract}
Introduction: Childhood obesity has now been recognized as a global health problem because of its devastating consequences and prevalence at uncontrollable rate worldwide. The objective of this study was to determine prevalence of obesity and find out the knowledge on obesity among school going adolescents. Material and Methods: This descriptive cross-sectional study was conducted among adolescents of two private schools of Kaski district. Altogether 120 adolescent students were selected using census method. Height and weight were measured with standard scale and BMI was calculated. Selfadministered structured questionnaire was used to assess knowledge. Descriptive statistics and Chi-square test at 0.05 significance level was used to analyze data.Results: The mean age of adolescents was 15.1 years and $50 \%$ of them were male. The prevalence of obesity among adolescents was $3.3 \%$. Seventy five percent of the adolescents had knowledge regarding meaning of obesity and $59.2 \%$ had mentioned high calorie intake as a risk factor of obesity. Likewise, $52.5 \%$ adolescents stated Diabetes mellitus as consequence of obesity. Ninety eight percent mentioned regular exercise as a preventive measure of obesity. More than three fourth (78.3\%) of the adolescents had inadequate knowledge regarding obesity. Male adolescents had significantly higher knowledge than female adolescents $(p=0.00)$.Conclusion: Even though very few adolescents had obesity, there were adolescents with overweight which were at more risk for getting obesity. Adolescents have inadequate knowledge regarding obesity.
\end{abstract}

Key words: Obesity, Adolescents, Prevalence, Knowledge

\section{Introduction}

$\mathrm{O}_{2}$ besity has reached epidemic proportions globally, with at least 2.8 million people dying each year as a result of being overweight or obese. Once associated with high-income countries, obesity is now also prevalent in low- and middle-income countries. ${ }^{1}$. Also, $44 \%$ of the diabetes burden, $23 \%$ of the ischemic heart disease burden and between $7 \%$ and $41 \%$ of certain cancer burdens are attributable to overweight and obesity ${ }^{2}$.The problem of obesity is steadily affecting many low and middle-income countries, particularly in urban settings ${ }^{1}$. Prevalence of obesity and overweight was $4.9 \%$ in Asia $^{3}$. In Nepal,
${ }^{1}$ Apsara Pandey, Lecturer, Maharajgunj Nursing Campus, Institute of Medicine, Tribhuwan University, Kathmandu, Nepal, ${ }^{2}$ Sony Sapkota, Register Nurse, Western Region Hospital, Kaski, Nepal.

\section{Address for correspondence}

Apsara Pandey, Master in Pediatric Nursing, Lecturer, Maharajgunj Nursing Campus, Institute of Medicine

E-mail: pkapsara@gmail.com

\section{Acknowledgements: None \\ Funding: Nil \\ Conflict of Interest: None \\ Permission from IRB: Yes}

\section{How to cite}

Pandey A, Sapkota S. Prevalence and Knowledge on Obesity Among School Going Adolescents of Kaski, Nepal. J Nepal Paediatr Soc 2018;38(2):63-68.

doi: http://dx.doi.org/10.3126/jnps.v38i2.19917

This work is licensed under a Creative Commons Attribution 3.0 License.

\section{(c) (i)}


$4.0 \%$ and $21.6 \%$ adult population are obese and overweight respectively. ${ }^{4}$

The consequences of childhood and adolescent obesity are far reaching, not only including healthrelated physical outcomes, such as high blood pressure, high cholesterol, metabolic syndrome, type 2 diabetes, orthopedic problems, sleep apnea, asthma, and fatty liver disease, but also psychological, social and behavioral consequences, such as risk for problems related to body image, self-esteem, social isolation and discrimination, depression, and reduced quality of life. ${ }^{5}$

In order to promote healthier eating habits and consequently to decrease the rate of obesity; knowledge about food, nutrition and healthier physical activity is believed to be important ${ }^{6}$. But very little study was done regarding prevalence and knowledge on obesity among school adolescents in Nepal. So,this study was intended to determine prevalence of obesity and find out the existing knowledge on obesity among school adolescents.

\section{Material and Methods}

The descriptive cross-sectional research design was used for this study. Altogether 120 school adolescents studying in grade 10 of SOS Hermann Gmeiner School (90 students), and Karuna Nidhi Education Foundation Higher Secondary School (30 students), Kaski were selected using census method. Convenience sampling methods was used to select schools. Both male and female students were included in the study. Data were collected using pre-tested self administered questionnaires. Height and weight of each adolescent was measured and recorded.

A portable Measuring Board with a base for standing upon and a right angle headpiece was used for measuring height. Similarly, Digital Weighing Scale was used to measure the weight. Prior to data collection, formal permission was taken from school administration and informed was obtained from the both adolescents and their parents of each. The collected data were checked, reviewed and organized for its completeness and accuracy. Data were edited, categorized, coded, entered and analyzed by using Statistical Package for Social Science (SPSS) version 16.The data were analyzed using frequency, percentage, mean and standard deviation and Chi-square test was used to measure the association between selected variables and adolescent's level of knowledge.

Obesity was measured by body mass index (BMI) which is defined as the weight in kilograms divided by the square of the height in meter $(\mathrm{kg} / \mathrm{m} 2)$. BMI level was calculated by percentile ranking for adolescents by plotting the BMI of each adolescent on BMl-for-age growth chart of World Health Organization (for either girls or boys).

Scoring system was adopted to find out the adequacy of knowledge. For each right response score 1 was given and 0 for wrong and don't know responses. The total obtainable score was 63 . Adequacy of the knowledge was graded based on the $50 \%$ of maximum scores as adequate and less than $50 \%$ of score as inadequate knowledge.

\section{Results}

The study results were presented in sociodemographic variables, prevalence of obesity, level of knowledge and association between selected variables and knowledge on obesity, prevalence of obesity.

\section{Socio-demographic Variables}

The mean age of the adolescents was 15.08 years with Standard deviation of 0.656 . Half $(50 \%)$ adolescents were male, majority of the adolescents $(67.5 \%)$ were Brahmin/Chhetri and about two third of the adolescents $(71.7 \%)$ were from urban residence. The majority of the adolescents were Hindu (86.7\%). Most of the adolescents (83.3\%) were from nuclear family. Regarding the parental education, literacy rate among adolescent's mothers was $94.2 \%$ and majority $(54.2 \%)$ was SLC and intermediate level. Similarly, the literacy rate among adolescent's fathers was $97.5 \%$ among which majority $(45.8 \%)$ were graduate and postgraduate. Likewise, most of the adolescent's mothers were housewives $(57.5 \%)$ and fathers were service holder (59.2\%) (Table1).

\section{The Prevalence of Obesity among Adolescents}

The prevalence of obesity among adolescents was only $3.3 \%$. Likewise, $10 \%$ of the adolescents were overweight while $77.5 \%$ were healthy weight and $11 \%$ were underweight (Table 2).

\section{Adolescents' Level of Knowledge regarding Obesity}

Out of total adolescents, majority (78.3\%) of adolescents had inadequate knowledge whereas only $21.7 \%$ of adolescents had adequate knowledge regarding obesity. Majority (40.0\%) of adolescents had got information from schools teachers followed by family friends $30.8 \%$ news paper $30 \%$ health worker and radio/TV $24.2 \%$ (Table 3 ).

Association between Adolescent's Level of knowledge and socio-demographic Variable

Association between adolescent's level of knowledge and socio-demographic variables showed that there is significant relation between adolescent's 
level of knowledge and sex since the $p$ value is less than $0.05(P=0.00)$. But there is no any association between other variables such as area of residence and type of family and family history of obesity since the $p$ value is greater than 0.05 ( $p$ value $=0.245,0.843,0.268)$ (Table 4). There is no association between prevalence of obesity among adolescents with their level of knowledge (Table 5).

Table 1: Socio-demographic Variables of Adolescents $(n=120)$

\begin{tabular}{|c|c|c|}
\hline Variables & Number & Percent (\%) \\
\hline \multicolumn{3}{|l|}{ Sex } \\
\hline Male & 60 & 50.0 \\
\hline Female & 60 & 50.0 \\
\hline \multicolumn{3}{|l|}{ Ethnicity } \\
\hline Brahmin/ Chhetri & 81 & 67.5 \\
\hline Newar & 7 & 5.8 \\
\hline Janajati & 25 & 20.8 \\
\hline Dalit & 5 & 4.2 \\
\hline Others & 2 & 1.7 \\
\hline \multicolumn{3}{|l|}{ Area of residence } \\
\hline Rural & 34 & 28.3 \\
\hline Urban & 86 & 71.7 \\
\hline \multicolumn{3}{|l|}{ Parent's educational status } \\
\hline \multicolumn{3}{|l|}{ Mother } \\
\hline Illiterate & 7 & 5.8 \\
\hline Informal education & 4 & 3.3 \\
\hline Primary education & 4 & 3.3 \\
\hline Secondary education & 13 & 10.8 \\
\hline SLC and intermediate & 65 & 54.2 \\
\hline Graduate and postgraduate & 27 & 22.5 \\
\hline \multicolumn{3}{|l|}{ Father } \\
\hline Illiterate & 3 & 2.5 \\
\hline Primary education & 3 & 2.5 \\
\hline Secondary education & 10 & 8.3 \\
\hline SLC and intermediate & 49 & 40.8 \\
\hline Graduate and postgraduate & 55 & 45.8 \\
\hline \multicolumn{3}{|l|}{ Parent's Occupation } \\
\hline \multicolumn{3}{|l|}{ Mother } \\
\hline Agriculture & 3 & 2.5 \\
\hline Housewives & 69 & 57.5 \\
\hline Business & 20 & 16.7 \\
\hline Service & 28 & 23.3 \\
\hline \multicolumn{3}{|l|}{ Father } \\
\hline Agriculture & 5 & 4.2 \\
\hline Business & 44 & 36.7 \\
\hline Service & 71 & 59.2 \\
\hline
\end{tabular}

Table 2: Prevalence of Obesity among Adolescents $(n=120)$

\begin{tabular}{|c|c|c|}
\hline Prevalence of Obesity & Number & Percent (\%) \\
\hline Underweight (Less than 5th percentile) & 11 & 9.2 \\
\hline Normal / Healthy weight (5th percentile to less than 85th percentile & 93 & 77.5 \\
\hline Overweight (85th to less than 95th percentile) & 12 & 10.0 \\
\hline Obese (Equal to or greater than 95th percentile) & 4 & 3.3 \\
\hline
\end{tabular}


Table 3: Adolescents' Level of Knowledge and sources of Information regarding Obesity $(n=120)$

\begin{tabular}{lcc}
\hline Variables & Number & Percent \\
\hline Level of Awareness & & 21.7 \\
\hline Adequate & 26 & 78.3 \\
\hline Inadequate & 94 & 30.0 \\
\hline Sources of Information & & 24.2 \\
\hline Newspaper/ magazines/ posters/ pamphlets & 36 & 24.2 \\
\hline TV/Radio & 29 & 40.0 \\
\hline Health worker & 29 & 18.3 \\
\hline School teacher & 48 & 30.8 \\
\hline School curriculum & 22 & 37 \\
\hline
\end{tabular}

Table 4: Association between socio- demographic variables and Adolescent's Level of Knowledge $(n=120)$

\begin{tabular}{|c|c|c|c|c|}
\hline \multirow{2}{*}{ Variables } & \multicolumn{2}{|c|}{ Knowledge } & \multirow{2}{*}{ Chi-square } & \multirow{2}{*}{$p$-value } \\
\hline & Adequate & Inadequate & & \\
\hline & No. (\%) & No. (\%) & & \\
\hline \multicolumn{5}{|l|}{ Sex } \\
\hline Male & $23(88.5 \%)$ & $37(39.4 \%)$ & 19.64 & 0.00 \\
\hline Female & $3(11.5 \%)$ & $57(60.6 \%)$ & & \\
\hline \multicolumn{5}{|c|}{ Type of family } \\
\hline Nuclear & $5(19.2 \%)$ & $29(30.9 \%)$ & 1.354 & 0.245 \\
\hline Joint & $21(80.8 \%)$ & $65(69.1 \%)$ & & \\
\hline \multicolumn{5}{|l|}{ Residence } \\
\hline Rural & $22(84.6 \%)$ & $78(83 \%)$ & 0.39 & 0.843 \\
\hline Urban & $4(15.4 \%)$ & $16(17 \%)$ & & \\
\hline \multicolumn{5}{|c|}{ Family history of obesity } \\
\hline Present & $17(25.4 \%)$ & $50(74.6 \%)$ & 1.228 & 0.268 \\
\hline Absent & $9(17.0 \%)$ & $44(83.0 \%)$ & & \\
\hline
\end{tabular}

Table 5: Association between Prevalence of Obesity and Knowledge regarding Obesity

\begin{tabular}{lcccc}
\hline \multirow{2}{*}{ Variables } & \multicolumn{2}{c}{ Knowledge } & \multirow{2}{*}{ Chi-square } & \multirow{2}{*}{ p-value } \\
\cline { 2 - 3 } & Adequate & Inadequate & & \\
\hline Normal weight and below & No $(\%)$ & No $(\%)$ & & 0.728 \\
\hline Above normal & $22(86.6 \%)$ & $82(87.2 \%)$ & 0.121 & \\
\hline
\end{tabular}

\section{Discussion}

In this study, $100 \%$ of the adolescents have heard about obesity through different sources. Among them forty percent of the adolescents mentioned that they had heard about obesity from school teachers and least (24.2\%) mentioned TV/Radio as a source of information. This finding contradicts with the findings of the study done in Malaysia which revealed Television (73.3\%) as a major source and school teachers $(10 \%)$ as a least mentioned source of information regarding obesity ${ }^{7}$.

This study shows majority $(77.5 \%)$ of adolescents were healthy weight, $10 \%$ were overweight and only $3.3 \%$ were obese. This finding is parallel with the findings of one study which reported that $85.6 \%$ of children were healthy weight, almost $10 \%$ of them were overweight and only $4.5 \%$ children were obese ${ }^{8}$. This study is also consistent with another study conducted among higher secondary level adolescents with 5.8\% overweight and $2.3 \%$ obese $^{9}$. Similarly, this is also parallel with the findings of another one study which showed the prevalence of overweight of $12.2 \%$ among adolescents $^{10}$.

More than two third $(75.0 \%)$ of the adolescents in this study were able to define obesity correctly which is consistent with the findings of the onestudy which showed $82.21 \%$ of students defined obesity correctly ${ }^{11}$. Likewise, in this study only $26.7 \%$ of the adolescents correctly mentioned the method of assessment of obesity using BMI. This finding contradicts with the findings of the study which showed $66.82 \%$ responded correctly about BMI. ${ }^{11}$. 
In this study more than half $(59.2 \%)$ of the adolescents mentioned high fat containing food as a risk factor for obesity which contradicts with the finding of the study where only $12.01 \%$ mentioned highest fat containing food as a risk factor ${ }^{11}$. Similarly, $25.0 \%$ adolescents identified obesity as a genetic problem and $17.5 \%$ identified stress as risk factor which contradicts with the findings of another study which reported $14.5 \%$ as genetic susceptibility and $32.6 \%$ as stress as risk factor for obesity ${ }^{12}$.

The study shows that majority $(78.3 \%)$ of adolescents had inadequate knowledge. This result is supported by findings of other study conducted among 100 adolescents which revealed that $67 \%$ had inadequate knowledge and only $32 \%$ had moderately adequate knowledge ${ }^{13}$. This result is also parallel with the study done in another 100 adolescents which showed that $93.0 \%$ of the adolescents had below average knowledge regarding obesity ${ }^{14}$

In this study, male adolescent students had significantly higher awareness (88.5\%) than female $(11.5 \%)$ adolescent students regarding obesity. This finding is parallel with another one finding of which resulted that male students had more knowledge than female adolescent students ${ }^{14}$. There was no significant association between selected socio-demographic variables (area of residence and type of family) and knowledge level of adolescents. This study contradicts with the finding of another one study which shows significant association between knowledge level of adolescents with area of residence and type of family ${ }^{13}$.

Association between knowledge level and prevalence of obesity was not significant in this study. This is supported by the study which revealed insignificant association between knowledge regarding obesity and body mass index (BMI) level of adolescents ${ }^{13}$.

\section{Conclusion}

In conclusion, majority of the adolescents had inadequate knowledge regarding obesity. Even though very few adolescents had obesity, there were adolescents with overweight which were at more risk for getting obesity; among which male adolescents were obese while most of the female adolescents were overweight.

\section{Recommendation}

It is recommended to conduct health programme regarding prevention of obesity in schools and provide information through school teachers as well as through mass media to increase knowledge regarding obesity.

\section{References}

1. World Health Organization Ten Facts on Obesity Geneva: World Health Organization. Updated October 2017. Available from http://www.who.int/features/ factfiles/obesity/en/

2. European Association for the Study of Obesity. Obesity facts and figures, 2013. Available from http://easo.org/ education-portal/obesity-facts-figures

3. Balarajan Y, Villamor E. Nationally representative surveys show recent increases in prevalence of overweight and obesity among women of reproductive age in Bangladesh, Nepal and India. J Nutri [Internet]. 2009; 139(11): 2139-44; DOI: 10.3945/jn.109.112029

4. Ministry of Health and Population, Nepal Health Research Council and World Health Organization. Non communicable diseases risk factors: STEPS survey Nepal, 2013: Kathmandu. Available from non communicable_diseases_risk_factors_steps_survey_ nepal_2013..pdf

5. Pulgaron ER, Childhood obesity: a review of increased risk for physical and psychological co-morbidities.PMC [Internet]. 2013 Jan; 35(1): A18-A32. doi: [10.1016/j. clinthera.2012.12.014]

6. Triches RM, Giugliani, ERJ. Obesity, eating habits and nutritional knowledge among school children. Revusta de Saude Publica [Internet]. 2005;39 (4). doi: doi. org/10.1590/S0034-89102005000400004

7. Baig M, Sulaiman S, Gillani S, Hariadha E. A preliminary study on knowledge about obesity in Pulau Pinang, Malaysia. Int J Pharm \& Life Sci [Internet]. 2013 June; 4(6). Available from http://www.ijplsjournal. com/issues\%20PDF\%20files/june-2013/2.pdf

8. Vitariusova E, Babinska K, Kostalova L, et al. Food intake, leisure time activities and the prevalence of obesity in school children in Slovakia. Cent Eur J Public Health [Internet]. 2010; 18(4):192-197doi: doi: 10.21101/cejph.a3607

9. Kaur R, Kumari R. Samuel. A study to assess the knowledge and attitude of adolescents on obesity at selected senior secondary schools in Amritsar in a view to develop and distribute information booklet. Int J Edu Applied Resea [Print]. 2014 Jan-June; 4(1):35-9.

10. Acharya B, Chauhan HS, Thapa, SB, Kaphle, HP, Malla D. Prevalance and socio-demographic factors associated with overweight and obesity among adolescents in Kaski district, Nepal. Indian J Comm Health. 2014 Dec; 26 (2), suppl S2 :118-22(2). 
11. Piryani S, Baral K, Pradhan B, Poudyal A, Piryani, $R$. Overweight and its associated risk factors among urban school adolescents in Nepal: a cross-sectional study. British Med J [Internet].2015; 6(5). doi: 10.1136/ bmjopen-2015-010335

12. Samudre M, Kulkarni SM. Knowledge on prevention of obesity among the students from selected high schools. J Sci \& Resea. 2016 March;5(3): 682-7. doi: NOV161975
13. Shrivastava S, Shrivastava P, Ramasamy J. Assessment of knowledge about obesity among students in a medical college in Kancheepuram district, Tamil Nadu. Prog health Sci [ Internet]. 2013 (3) 1:5460. doi bwmeta1.element.ceon.element-4aafc6a00ec9-3e94-999b-25c3d1c2025b

14. Mangalathil T, Kumar P, Choudhary V. Knowledge and attitude regarding obesity among adolescent students of Sikar, Rajasthan. J Nur Health Sci [Internet].2014 March- April; 3(2): 2320-40. doi: 10.9790/195903214448 